\title{
6 The social economy and renewable resource development in Nunavut
}

\author{
Barriers and opportunities
}

\author{
Chris Southcott
}

\section{Introduction}

Nunavut and the rest of Canada's North has undergone tremendous social, cultural, and economic change over the past 60 years. Northern communities have experienced processes of development quite different from most other communities in Canada. These processes have resulted in many unique challenges. These challenges have been met by communities developing approaches that serve to assist these communities to ensure healthier and more sustainable futures. While increased attention is being devoted to the importance of non-renewable extractive developments in the region, these other approaches remain important and are being utilised to support renewable resource development in the region.

One of these new approaches is that of the social economy (Bouchard, 2011; Quarter, Mook, \& Armstrong, 2017). It is a means of social action which seeks to empower communities by developing social capital and human capital capacity through assisting non-profit, voluntary, and cooperative organisations work more effectively in the interests of their communities. This chapter summarises research done to examine the potential of the social economy to assist Northern communities to deal with changes these communities are experiencing. It is an attempt to provide a "portrait" of the social economy in Nunavut and to outline the barriers and opportunities. It is based largely on the results of a survey of social economy organisations undertaken in Northern Canada in 2008.

Data from this survey shows that when compared to the other Northern territories, Nunavut has a much higher percentage of social economy organisations engaged in activities that elsewhere are provided by profitoriented private sector organisations. Many of these are engaged in renewable resource development. It also shows that social economy organisations in Nunavut tend to be younger than those elsewhere in Canada and that Nunavut has a much smaller percentage of organisations that are legally registered as charitable organisations. Membership numbers for social economy organisation show healthy growth with a relatively high level of activity, although fewer of these organisations use volunteers than in the 
other territories. In terms of challenges, obtaining and retaining paid staff is one of the most important along with decreasing government funding. In terms of general needs faced by social economy organisations, Nunavut respondents identified finding funding as the most important overall need followed by providing staff training and development.

Findings confirm that social economy organisations continue to be an important part of community developments in Nunavut and that they are a significant contributor to the renewable resource sector. Despite challenges, these organisations continue to be an important part of any attempt to resist an overdependence on extractive industry development in the region. While extractive industry development may continue to be important in Nunavut, a review of problems being experienced by social economy organisations suggest that communities could potentially use financial, training, and other benefits from non-renewable resource development to help social-economic organisations better contribute to renewable resource development.

\section{The social economy and development in Nunavut}

Until World War II, Nunavut was isolated from many of the changes occurring in the rest of Canada. The Inuit people of the region were able to maintain their traditional lifestyles: lifestyles both supported and challenged by the interests of the fur trade. This started to change with military development during the World War II. The establishment of military installations in the region introduced new influences and created infrastructure such as airbases that allowed for increased exposure to southern influences after the war.

Almost from the beginning of this change, there was a debate about how the "modernisation" of the North should be managed. The fur trading industry and the Canadian government first thought it best to keep the Indigenous population as isolated as possible from the forces of change (Damas, 2002). Continued dependence on their traditional activities was considered to be the best option for the Inuit peoples of the region. During the 1950s, the federal government reversed its policy on the issue and decided that as Canadian citizens, the Indigenous peoples of the North had a right to basic services such as education, health, and social services. These could best be provided by establishing permanent settlements for the Inuit people of the region.

Yet it was recognised that the North would not be simply an extension of the urban life of the southern parts of Canada. The communal and sharing culture that was the basis of traditional Inuit culture should be maintained by special approaches to development. Co-operatives and community economic development initiatives were highlighted (Lotz, 1982; MacPherson, 2000; Pell, 1990). With the assistance of the federal government, the Inuit people of Nunavut established co-operatives as the main vehicles for economic development in their communities. The people of the region tried to ensure that Inuit traditional ways and knowledge became part of the 
economic development of their communities by using community-based initiatives. With the negotiation and signing of new treaties, these alternative approaches became institutionalised by the Indigenous peoples themselves in their attempts to maintain traditional activities (Saku, 2002).

The economic institutionalisation of Inuit traditions through a preference for community-based or social economy, initiatives is seen in the Nunavut Economic Development Strategy (NEF, 2003), the first development strategy developed following the creation of Nunavut. Its guiding principles link IQ with "placing control of economic development in the hands of community members" and "integrating economic development activities with community efforts in the areas of community wellness, community learning and community governance." Social economy organisations are clearly identified as important agents of desirable economic development.

These ideals were reiterated in subsequent updates on the Strategy produced by the Nunavut Economic Forum (Impact Economics, 2005, 2008a). In 2007 and 2008, two separate studies were commission by the Nunavut Economic Forum to look at non-profit organisations and their role in the development of Nunavut. The 2007 study was the first to try and get a general idea of the situation of non-profits in Nunavut and the challenges that they face (Aarluk Consulting, 2007). As is noted later on in this report, the conclusions of the 2007 study are similar to those found in this report: non-profits are essential elements of Nunavut communities, but they are faced, by funding and human resource difficulties. Further analysis of the situation in 2008 confirmed and elaborated on the findings of the 2007 study but highlighted the important potential of the non-profit sector to improve well-being in Nunavut's communities (Impact Economics, 2008b).

The Government of Nunavut Report Card, evaluating the performance of Nunavut ten years after its formation, noted that improvements could be made to make Nunavut a better place to live (North Sky Consulting, 2009). In many ways, the Report Card was a reiteration of points made in the initial Nunavut Economic Development Strategy. It noted the need for greater involvement of people in their community and their government. Greater involvement would assist in ensuring a greater degree of self-reliance and ensure that more effective education and training, housing, poverty reduction, and cultural programs are developed and delivered. Although the Report Card did specifically state the usefulness of social economy organisations in making these improvements, the previously mentioned reports all noted the importance of community-based, non-profit and voluntary organisations in achieving greater community involvement.

\section{The conditions of the social economy in the Canadian North}

Indigenous traditions linked to the mixed economy, the role of the state, and dependence on natural resource exploitation can be expected to have an impact on the type, form, operation, and development of social economy 
organisations in the Canadian North. Each of these factors impact the social economy in different ways. It is not a simple matter of saying that this factor will have a positive impact or that factor will have a negative impact. The reality will be much more complex.

Indeed, we can discover initial clues to this complexity in the findings of the 2003 National Survey of Non-profit and Voluntary organisations. While publicly available data from this survey does not allow in-depth investigation of social economy organisations in the north, a 2005 report from this study did list some interesting statistics related to the situation of non-profit and voluntary organisations in the three northern territories (Statistics Canada, 2005). It should be pointed out that this data does not include all social economy organisations. In particular cooperatives, an important part of many communities in the North, were not included in the 2003 survey. The study did not allow for a comparison of Nunavut with the other regions of the Canadian North.

The study counted 851 organisations in the Territories. It is interesting to note that this was the highest percentage of social economy organisation per population in Canada. At 825 organisations per 100,000 population, the percentage was significantly more than the Canadian average of 508 per 100,000 population (Statistics Canada, 2005, p. 19). Only a minority of these organisations are Registered Charities. At 37\%, this rate is the lowest in the country and significantly less than the national average of $56 \%$ of organisations that are Registered Charities (20). Not surprisingly, compared to the provinces, the Territories had the highest percentage of non-profit or voluntary organisations serving Aboriginal communities (20).

The study listed interesting financial characteristics of social economy organisations in the North. Organisations in the Territories had average revenues of $\$ 1.4$ million. This was higher than the average of organisations in all other provinces in the country (Statistics Canada, 2005, p. 30). Compared to the provinces, social economy organisations in the Territories had the highest percentage of income from "Earned income" - fees for goods and services. This source comprised $57 \%$ of all income for these organisations in the north.

Data showed that social economy organisations in the North varied from other provinces by primary activity. The Territories had the highest percentage of organisations involved in Law, Advocacy, and Politics (Statistics Canada, 2005, p. 19). The region also had higher than average percentages of organisations involved in Arts and culture, Sports and recreation, Education and research, the Environment, and Business and professional associations and unions. The region had lower percentages of organisations involved in health, social services, development and housing, grant-making, fundraising, and voluntarism promotion, and religion.

The study also showed that social economy organisations in the Territories were most likely to report problems related to organisational capacity (Statistics Canada, 2005, p. 53). Interestingly the one capacity area 
where they did not have problems was obtaining board members. Northern organisations are also far more likely to report problems, such as difficulty providing training to board members (52\% in the territories versus $34 \%$ in Canada); difficulty providing staff training and development ( $45 \%$ versus $27 \%$ ), and, difficulty obtaining the type of paid staff the organisation needs (44\% versus $28 \%$ ).

Many of these conditions were investigated further in an inventory, or portrait, of the social economy in Northern Canada undertaken by the SERNNoCa research project (Abele \& Southcott, 2016; Southcott, 2015). This attempt at a mapping of the social economy of the Yukon, Northwest Territories, Nunavut, Nunavik, and Labrador involved two stages. The first was a "census" of all social economy organisations in the Canadian North. A list of all possible social economy organisations with their main activity and location was constructed. The second was a questionnaire survey in order to uncover some of the basic characteristics of these organisations in comparison with other regions of Canada.

SERNNoCa researchers were very much aware that much social economy activity, especially in smaller northern communities that rely heavily on the mixed economy, is not undertaken by the formal organisations that this portraiture work was researching. Much of this activity is done in a much more informal manner that can only be studied using different techniques. Other research projects were undertaken by SERNNoCa to try and better understand this aspect of the social economy in the North (Abele, 2009; Natcher, 2009).

No single list exists for all social economy organisations in the North. As a result, an important first step in the portraiture process was the construction of this list. Before the list could be assembled, researchers had to decide on a definition of what constitutes a social economy organisation. The mapping exercise used in this project is based upon a broad definition of social economy that refers to activities that focus on serving the community rather than generating profits. The focus is on economic activities that are not primarily state-driven and not primarily profit-driven and include the traditional economies of Indigenous populations of the North. While a literature review of definitions was conducted, the project leaned most heavily on the definitions contained in Bouchard, Ferraton, and Michaud (2006).

Creating a list of social economy organisations in the Canadian North proved to be problematic. This was particularly the case with many Aboriginal organisations that undertake activities similar to social economy organisations but that are the products of treaties giving sovereign power to these communities. As it was pointed out by at least one questionnaire respondent, to include these organisations as a social economy organisation is to deny the legitimacy of these self-government initiatives. Provisional lists of social economy organisations were established in 2006 and 2007 to serve as the sample frame for the initial questionnaire survey. Table 6.1 shows the numbers for each region of the Canadian North for 
Table 6.1 Provisional list of social economy organisations in Northern Canada

\begin{tabular}{llll}
\hline & First Nations es Inuit Organizations & $\begin{array}{l}\text { Nonprofit } \\
\text { organizations }\end{array}$ & and volunteer \\
\hline Yukon & 40 & 482 \\
NWT & 153 & 475 \\
Nunavut & 35 & 309 \\
Nunavik & 19 & 46 \\
Labrador & 36 & 172 \\
\hline
\end{tabular}

these initial provisional lists. These lists included all potential social economy organisations and as such it was recognised at the time that the actual census list of social economy organisations would be smaller.

The construction of the list of social economy organisations gave researchers quite a bit of information about Northern social economy organisations independent of that gathered from the questionnaire. An extensive amount of information about these organisations can be gathered unobtrusively, directly from the internet. As concerns the Canadian North as a whole, as of May, 2008 1,190 organisations were identified as being probable social economy organisations (Southcott and Walker, 2009).

\section{The activities of social economy organisations in the Canadian North}

Internet-based research done on the census allowed researchers to identify the main activity of all but 28 organisations. These results are shown in Table 6.2.

These figures show several important differences in the types of social economy organisations that exist in each of the territories. In looking at Nunavut, compared to the averages for the Territorial North, it has a much higher percentage of social economy organisations engaged in trade, finance, and/or insurance. This is due primarily to the importance of co-operatives in the retail trade sector in Nunavut compared to the Northwest Territories and especially the Yukon. Another important difference concerning the social economy in Nunavut is the relative absence of organisations engaged in law, advocacy, and politics. This can be partially explained by the fact that many of the national advocacy groups have not established branches in Nunavut. Finally, Nunavut has a larger than an average number of organisations that are business associations, professional associations, or unions. The main reason for this is the fact that each community in Nunavut has a hunters and trappers association, the existence of which is linked to the 1993 Nunavut Land Claim Agreement. As well, there are more arts and 
Table 6.2 Social economy organisations in the territorial North by main activity

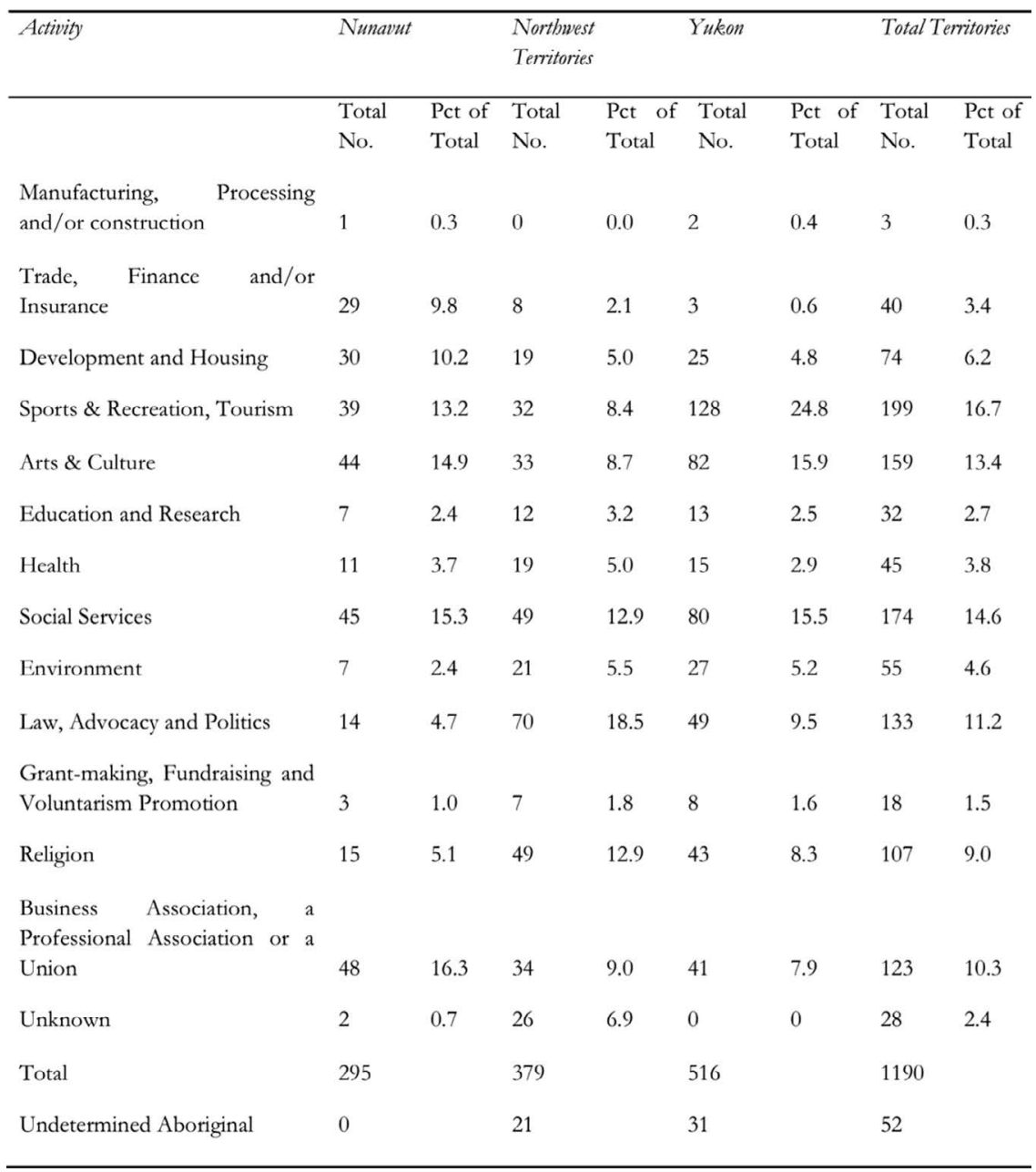

crafts business associations in Nunavut than in the other territories. This clearly shows the importance of social economy organisations for renewable resource development in Nunavut.

\section{The 2008 questionnaire survey of Nunavut social economy organisations}

The initial census served as the sampling frame for the 2008 questionnaire survey. In order to ensure that comparisons were eventually possible across Canada, the construction of the questionnaire was loosely based on a questionnaire designed by social economy research networks in both Atlantic Canada 


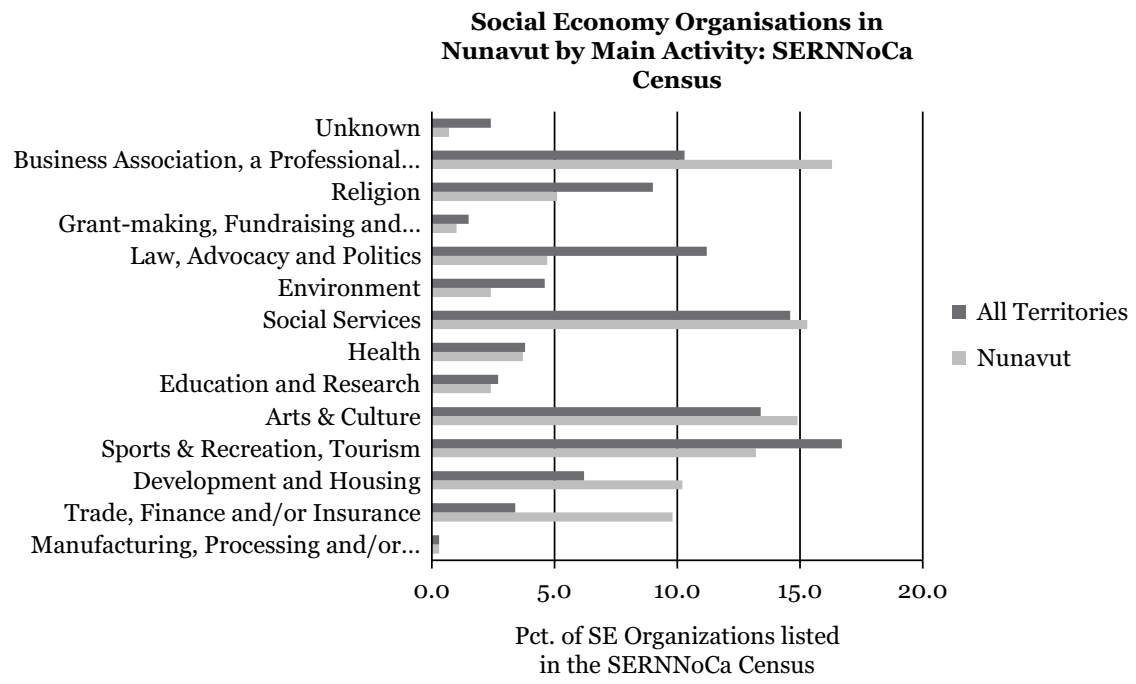

Figure 6.1 Social economy organisation in Nunavut by main activity: SERNNoCa Census.

and Southern Ontario. Due to the remoteness of many communities, it was decided to deliver the questionnaire using e-mail where possible and mail where this was not possible. In Nunavut, the questionnaire was sent out to 285 organisations. Just under half, 127 were sent out by mail and the rest by e-mail.

Looking at the results for the three Territories, it can be seen that a total of 153 questionnaires were returned from respondents identifiable as social economy organisations. This represents a response rate of $13 \%$. Looking at each of the territories, the Yukon had a response rate of $14 \%$, Nunavut had a response rate of $13 \%$, and the Northwest Territories of $11 \%$. The relatively low response rate from the questionnaire survey means that the results from the survey may not be representative of all social economy organisations in the Territories. At the same time, there was at least one indicator, which suggests that the results could be fairly representative. ${ }^{1}$ As noted above, we do have main activity statistics for the entire territories. When these are compared to the activity statistics for the questionnaire respondents, we see that the statistics for the two groups are remarkably similar. As well, the percentage of respondents from each territory is similar to the percentage of social economy organisations found in the census.

\section{Types of organisations}

Table 6.3 shows the types of organisations that responded to the questionnaire in both Nunavut and all three territories. We can see that the respondents in Nunavut had fewer non-profits, fewer voluntary organisations, and more cooperatives. 
Table 6.3 Structures of social economy organisations

\begin{tabular}{lll}
\hline Your organization is.... & & \\
\hline & Nunavut & All Territories \\
\hline a non-profit & 81.6 & 91.5 \\
a voluntary organization & 34.2 & 52.3 \\
a cooperative & 13.2 & 7.8 \\
& & 30.1 \\
a federation or association & 28.9 & 3.3 \\
organized as a worker cooperative & 5.3 & 64.7 \\
legally registered as a not-for-profit or charity & 50 & 26.1 \\
a subunit of a larger parent organization & 31.6 & \\
\hline
\end{tabular}

Looking at the data more closely, we see that there were fewer non-profits because there were more cooperatives and because some organisations, such as Hunter and Trappers organisations, are unsure whether they were non-profit or not. The relative importance of organisations created in association with the Nunavut Land Claims Agreement (NLCA) is a unique aspect of the social economy in Nunavut.

There were significantly fewer voluntary organisations in Nunavut that responded to the questionnaire than in the rest of the Territorial North. This could be an indication that the formal voluntary sector in Nunavut is smaller than elsewhere in the North, but more research needs to be done before this can be stated as a certainty. Several organisations that stated they were not voluntary organisations also stated that volunteers are used in various activities.

Legal differences among non-profit and voluntary organisations may influence the types of activities they undertake and their ability to access resources. A key distinction is between those organisations that are registered charities and those that are not. To better understand the key characteristics of the social economy organisation in Nunavut and the rest of Northern Canada, it is important to understand whether most organisations are part of larger organisations, legally constituted as a non-profit organisation, or a registered charity. It is also interesting to find out the percentage of social economy organisations that are organised as worker cooperatives, but this is a question that is included primarily to allow comparisons with other regions of Canada.

Table 6.3 shows that approximately $30 \%$ of the respondents in Nunavut were organised as a federation or association, a similar percentage to respondents in all the territories. Just over $31 \%$ were a subunit of a larger 
parent organisation, a somewhat higher percentage than for the territories as a whole. One of the most interesting findings is that only $50 \%$ of respondents stated that they were legally registered as a not-for-profit or charity. This is significantly less than the percentage of respondents in all the territories. While this difference is partially explained by the larger number of cooperatives among the respondents in Nunavut, it is clear that fewer social economy organisations in Nunavut are accessing the advantages that may come from a legal not-for-profit or charitable status.

\section{Age of organisations}

The national survey of non-profit and voluntary organisations done in 2003 showed that in Canada as a whole most of these types of organisations have existed in communities for a long time. The average age of organisations was 29 years. Organisations in Canada's North are much younger than the national average, reflecting the particular historical development of the North. Data from the 2008 survey showed that the average age of respondent organisations in all three territories was 21 years. Comparing the three territories, we see that Nunavut has the newest organisations, with an average age of 16 years, followed by respondent organisations in the NWT (21 years) and the Yukon (24 years).

Looking at Nunavut's organisations more closely, we see that co-operatives are by far the oldest organisations. The average age of Nunavut's co-operative organisations was 34 years. Some Hunter and Trappers organisations, though reorganised following implementation of the NLCA, also reported that they had existed for 30 years or longer. Almost $40 \%$ of Nunavut respondent organisations have been in existence for less than ten years, while almost $75 \%$ have been in existence for less than 25 years.

\section{The location of social economy organisations in Nunavut}

Figure 6.2 lists the percentages of respondent organisations by their main community of operations. As stated above, because of the low number of respondents, these percentages are not necessarily an adequate representation of the location of all social economy organisations in Nunavut. Still, in analysing the findings of the questionnaire, survey it is important to determine whether the sample of respondents is reasonably representative of the general population.

Without a better census of social economy organisations for Nunavut, population statistics are a good guide to tell us whether the respondents are reasonably representative of Nunavut social economy organisations. According to the 2006 Census, Iqaluit represents only $21 \%$ of the population of Nunavut, yet they represent $47 \%$ of our respondents. Respondents from Iqaluit are therefore probably over-represented. Cambridge Bay represents $5 \%$ of the population of Nunavut compared to the $8 \%$ of respondents for 


\section{Main location of respondent organisations}

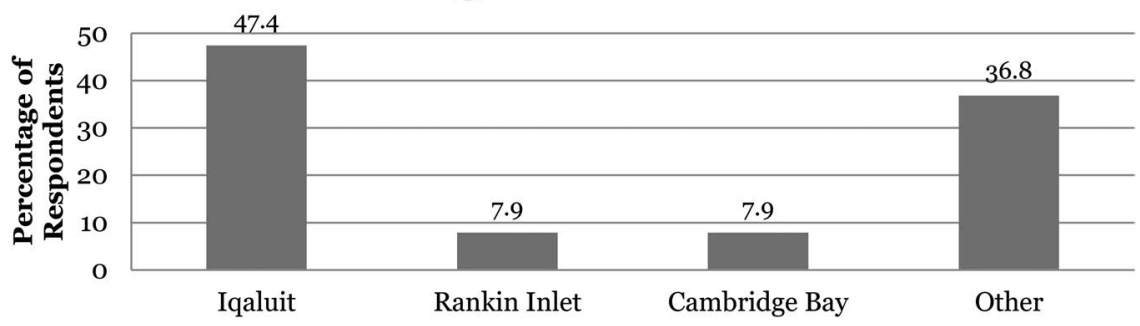

Figure 6.2 Main location of respondent organisations.

the questionnaire survey. Rankin Inlet has $8 \%$ of the population Nunavut as well as $8 \%$ of questionnaire respondents. Other communities in Nunavut represent $66 \%$ of the total population, yet only $37 \%$ of questionnaire respondents. organisations in these other communities are therefore probably underrepresented in our findings.

While Iqaluit is probably overrepresented, it is important to state that of the 18 organisations that listed Iqaluit as the main community operations, 7 also stated that they have operations in other communities. Only one organisation that listed their main community as outside Iqaluit, Rankin Inlet, or Cambridge Bay stated that they have operations in other communities.

\section{Membership}

One of the key strengths of social economy organisations is their members. Membership is sometimes restricted to certain individuals and at other times open to all. It is usually relatively easy to become a member of an organisation, and for this reason, the degree of involvement of members varies. An organisation that has an active membership has the potential to do much to both support the interests of the individual members and the community at large.

Not all organisations have members, but the majority does. The National Survey of Non-profit and Voluntary organisations showed that $76 \%$ of these organisations had members. Our survey showed that the percentage of respondent organisations in the Northern Territories with members was significantly higher at $86.3 \%$. The percentage of respondent organisations in Nunavut with members was $89.5 \%$.

For all three territories, 111 organisations were able to list the number of members, which totaled 56,901. This meant that respondent organisations had an average membership of 513. In Nunavut 26 respondent organisations were able to list the number of members, which totaled 29,683 for an average membership of 1,142 . It is important to note that membership numbers 
Table 6.4 Membership of respondent organisations by eligibility restriction

\begin{tabular}{lll}
\hline & All Territories & Nunavut \\
\hline Restricted & 38.6 & 47.4 \\
by Age & 5.9 & 10.5 \\
by Ethnocultural affiliation & 0 & 0 \\
by First Nations/Metis/Inuit affiliation & 7.2 & 15.9 \\
by Religion & 0.7 & 0 \\
by Geographic area & 7.2 & 2.6 \\
by Workplace affiliation & 2 & 2.6 \\
by Gender & 3.3 & 0 \\
\hline
\end{tabular}

varied greatly based on several criteria, such as the geographic area covered by the organisation and whether the membership was voluntary or related to pre-determined criteria such as land claims. A probable reason that the numbers for Nunavut were so high was that several organisations included all Inuit in a given area of Nunavut.

Some organisations have restrictions on who can become members. Table 6.4 shows the percentage of respondent organisations with restricted membership eligibility and the main characteristics of these restrictions. In the territories as a whole, $39 \%$ of all organisations had membership restrictions. In Nunavut, this percentage was slightly higher at $47.4 \%$.

When looking at the characteristics of these restrictions, we see that for all the territories, First Nation/Métis/Inuit affiliation and geographic area are the most important factors of restriction, while age and gender are also important. In Nunavut, by far the most important reason for membership restriction among questionnaire respondents was First Nation/Métis/Inuit affiliation. Almost $16 \%$ of questionnaire respondents stated their membership was restricted based on the criteria. Further examination shows that many of these organisations have restricted membership due to treaty requirements.

\section{Level of activity}

One indicator of the health of social economy organisations is whether their membership numbers are increasing or decreasing. Table 6.5 lists the growth or decline of memberships for respondent organisations from three years ago. Overall most organisations had membership numbers that were stable $-71.2 \%$ in all the territories and $61.8 \%$ in Nunavut. Very few organisations showed decreases in the number of members. In all the territories, $8.3 \%$ showed decline, while in Nunavut, $2.9 \%$, or one organisation, indicated their membership numbers were declining. Most declines were seen in the Yukon. 
Table 6.5 Levels of activity

\begin{tabular}{cll}
\hline & All Territories & Nunavut \\
\hline Change in number of members from 3 years earlier & & \\
Decreased & 7.2 & 9.7 \\
Stayed the same & 61.4 & 65.3 \\
$\quad$ Increased & 17.6 & 12.5 \\
Percentage of Membership attending AGM & & \\
0 to $25 \%$ & 23.5 & 21.1 \\
26 to $50 \%$ & 13.1 & 7.9 \\
51 to $75 \%$ & 15.7 & 26.3 \\
76 to $100 \%$ & 21.6 & 18.4 \\
\hline
\end{tabular}

Out of 11 organisations that indicated their membership was in decline, 7 were based in the Yukon. The highest percentage of organisations whose membership showed growth was found in Nunavut. For all the territories, $20.5 \%$ of organisations indicated that their membership had grown over the past three years, while in Nunavut, this percentage was significantly higher at $35.3 \%$.

An indicator of whether social economy organisations are active or not is whether they have regular annual meetings. As well, an active, well-organised organisation that is responsive to its membership would generally, but not in all cases, have a quorum at its Annual General Meeting (AGM) and would have the organisation's financial report approved. Data from the 2008 survey shows that the large majority of social economy organisations that responded to the questionnaire have AGMs and that these meetings have quorum and approve the financial reports of the organisation.

Looking at the percentage of the membership that attends AGMs, we see in Table 6.5 that there is a great deal of variety. For the territories as a whole the largest single category of participation of members is 0 to $25 \%$. For Nunavut, the largest category is that of $51 \%$ to $75 \%$. The frequency of general membership meetings is another indication of whether organisations are active or not. For the territories as a whole, respondent organisations held an average of 4.3 meetings a year for the general membership. For Nunavut, the number of meetings was significantly less at 2.5 meetings a year.

\section{Board activity and membership}

Generally speaking, social economy organisations are run by a smaller group of individuals who are more involved in the guiding the activities of the organisations. This smaller group of individuals is generally known 
as a governing Board. Information about the activity and composition of Boards can help us better understand the nature of social economy organisations. As can be expected, organisations held more Board meetings than general membership meetings. Looking at the respondent organisations in all three territories, an average of 7.6 Board meetings were held a year. In Nunavut alone, this number was slightly less at 6.6 meetings a year. The average number of Board members for respondent organisations in all the territories combined was 6.8 , while the number was slightly less in Nunavut at 6.4.

The survey respondents were asked if all their Board positions were filled or not. In both the territories as a whole and Nunavut $55 \%$ of the organisations responded that all the Board positions were filled, meaning that $45 \%$ had vacant positions. The vast majority of Board members are volunteers that receive no compensation for their participation. Of all the respondent organisations in all three territories, only $16.2 \%$ gave any sort of compensation to Board members. At the same time, there is a significant difference between Nunavut and the other territories in this regard. A much higher percentage of Nunavut organisation (35.2\%) gave compensation to its Board members.

Figure 6.3 shows the characteristics of Board members for those organisations that responded to the questionnaire. It is interesting to note that $55 \%$ percent of Board members in Nunavut are either First Nation, Métis, or Inuit while the corresponding figure for all the territories in $31 \%$. It is also interesting to note that while a majority of Board members in all the territories are female, only $35.2 \%$ of those in Nunavut are women.

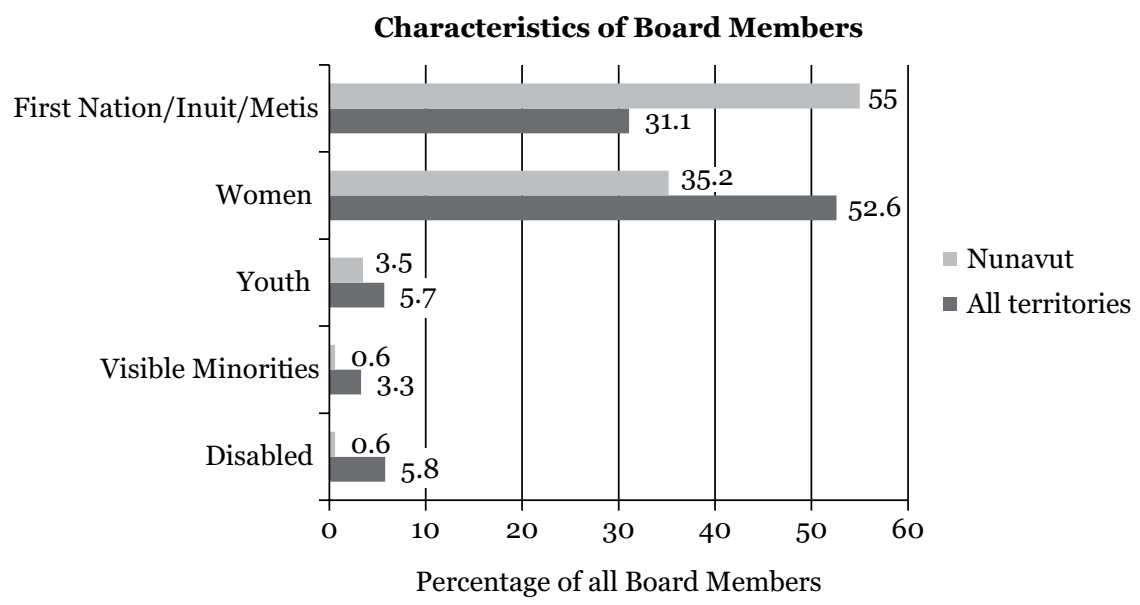

Figure 6.3 Characteristics of board members by percentage of all board members. 


\section{Volunteers and employees}

One of the most significant differences between Nunavut and the other territories is that fewer social economy organisations in Nunavut use volunteers for their activities. While $78.9 \%$ of respondents in all the territories use volunteers, only $55.3 \%$ of Nunavut respondents do.

In terms of the number of volunteers used by respondent organisations each year, there is a lot of variation. Looking at the Territories as a whole, most organisations used less than ten volunteers in a given year. The next largest category is 11 to 20 volunteers. Over $14 \%$ of respondent organisations used over 50 volunteers a year. The percentages of Nunavut are also included, but because of the small number of Nunavut respondents (22), the percentages are not very reliable.

In both Nunavut and the other territories, approximately $46 \%$ of respondents reported that their organisations had no paid employees and therefore issued no T4 slips. Of the remaining $54 \%$ of respondents, there was a significant difference between Nunavut and the rest of the territories in terms of the average number of employees per organisation. The average number of employees in respondent organisations in all the territories was 6.5, while in Nunavut, the average was much higher at 12 . Nunavut has a larger number of smaller organisations employing less than 40 people, while the other territories have a large number of bigger employers.

\section{Human Resource issues}

Respondents were asked if they had human resource problems. The most serious problems in this area relate to obtaining and retaining paid staff. Figure 6.4 shows that just over $30 \%$ of respondents in all territories said

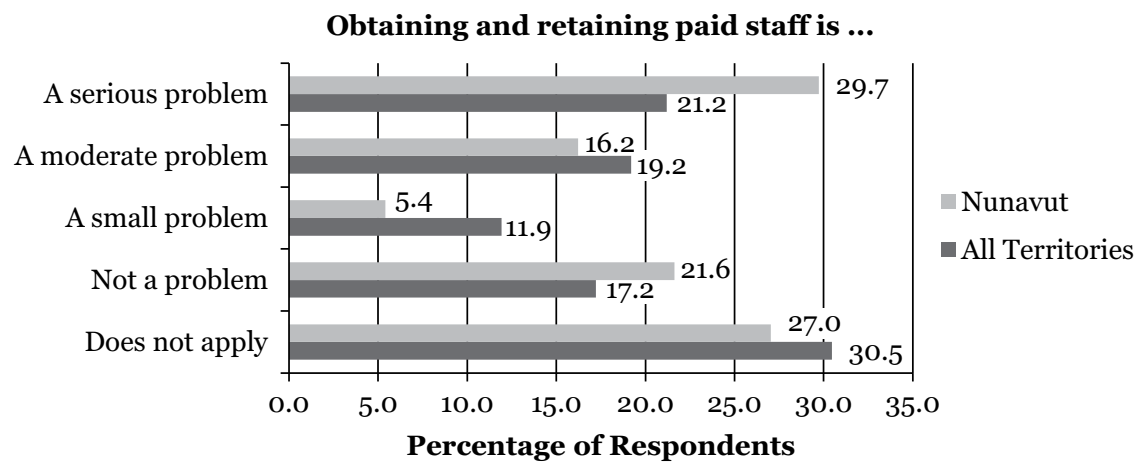

Figure 6.4 Percentage of respondents rating the statement "Obtaining and retaining paid staff is...." 
it was an issue that did not apply to them. Generally, this is because these particular organisations do not have paid staff. Just over $40 \%$ stated that this was either a serious or moderate problem. In Nunavut, just under $30 \%$ stated it was a serious problem. Next in importance was training. Just under $38 \%$ of Nunavut respondents listed providing staff training and development as a serious or moderate problem against $22 \%$ who said it was not a problem.

Obtaining and retaining Board members does not seem to be that much of a problem in Nunavut. While $30 \%$ of respondents agreed that it was either a serious or moderate problem, $38 \%$ said it was not a problem. Providing training to board members is the least serious problem. In Nunavut, less than $30 \%$ of respondents claimed it was a serious or moderate problem compared to over $40 \%$ who said it was not a problem.

\section{Finances}

In addition to the many contributions that social economy organisations make to communities, they also represent an important economic presence. The NSNPVO Survey showed that many non-profit and voluntary organisations earn income by providing goods and services for a fee; some also depend substantially on governments - particularly provincial governments - for funding. Smaller organisations rely heavily on donations of money and in-kind donations of goods and services.

Figure 6.5 shows the sources of revenue for social economy organisations in the North according to the 2008 survey. For respondents in all the territories $87.8 \%$ received funding from another organisation such as a government, a foundation, or a corporation. In Nunavut, this total was slightly less at $78.4 \%$. The largest single source for funding was from the government in the

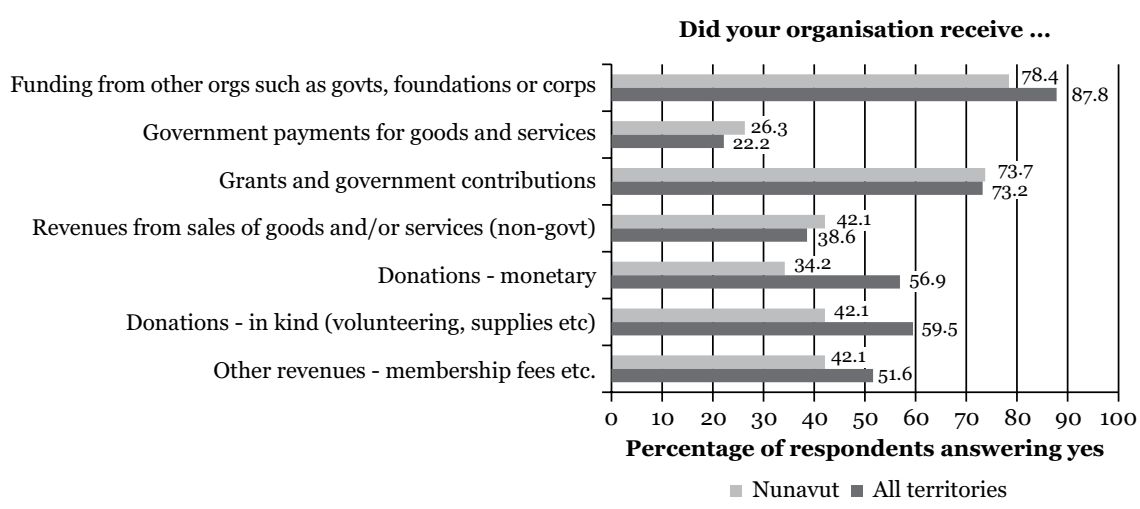

Figure 6.5 Graph of percentage of respondents answering yes to the statement "Did your organization receive...." 
form of grants or contributions. In all the territories, $73.2 \%$ of organisation received funding from this source compared to 73.7 in Nunavut. It is notable that the NSNPVO Survey of 2003 showed a much lower reliance on government sources in the rest of Canada, where only $49 \%$ of non-profits and voluntary organisations received government funding. In comparing Nunavut organisations with those in the rest of the North we can see that a slightly higher percentage of Nunavut social economy organisations receive funding from government payments for goods and services, non-government sales of goods and services, and a lower percentage receive funding from donations, either monetary or in-kind, and other types of revenues.

Respondents were asked whether their organisation's revenues had either increased, decreased, or stayed the same over the past three years. Only $12 \%$ of all the respondents in the North stated that their revenues had decreased and in Nunavut only one organisation did. A large percentage, $48 \%$ in all the territories and 48.6 in Nunavut stated that their revenues had increased over the past three years. This is an indication that these organisations are continuing to be a dynamic part of the economic makeup of the Canada's North.

The respondents were also asked if a series of financial issues identified in previous research were a problem for their particular organisation. The results are displayed in Figure 6.6. Of all the issues listed, the most serious for Northern social economy organisations was reductions in government funding. In all the territories, $44.8 \%$ of respondents stated that it was

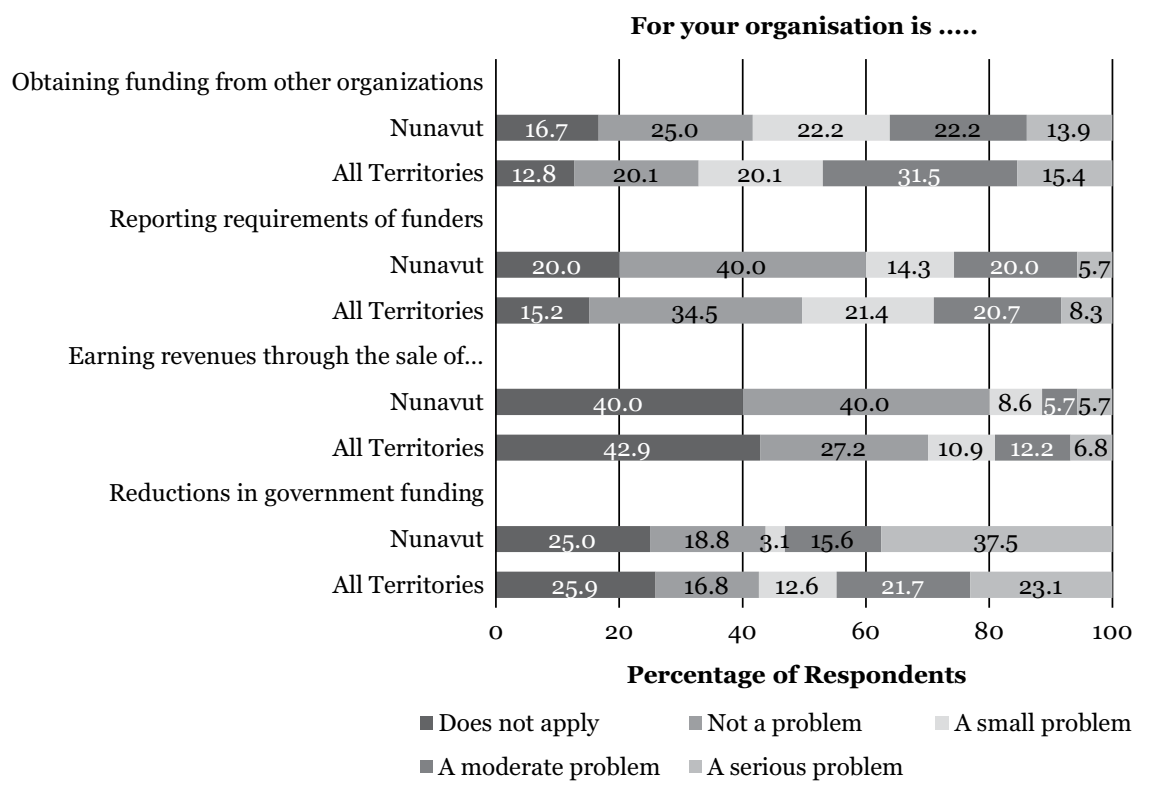

Figure 6.6 Graph of percentage of respondents rating the statement "For your organisation is..." for funding. 
a serious or moderate problem. In Nunavut the percentage was even higher at $53.1 \%$. In Nunavut, $37.5 \%$ of respondent organisations stated that reduction in government funding was a serious problem. Obtaining funding from organisations such as government, foundations or corporations was the second most important problem followed by the reporting requirements of funders. Earning revenues through the sale of goods and/or services was the least important problem for organisations in all the territories and in Nunavut.

Organisations were also asked if their organisation made a surplus profit last year from the sales of goods or services. There is a significant difference between the respondents in Nunavut and those in the other territories. Only $21.1 \%$ of respondents in all territories stated that they earned a surplus last year, whereas $38.3 \%$ of respondents from Nunavut did. While not many social economy organisations generate a surplus, respondents were asked what would happen if a surplus was generated. Clearly the most popular direction of distribution is back into the organisation - an option identified by slightly more than half of respondents, in both Nunavut and the other territories. The next most popular direction of distribution is to hold it in reserve for community benefit or in a community trust. In all the territories, $17 \%$ of the respondents favored this option while the percentage in Nunavut was slightly less at $13.2 \%$. In all the territories, only $4.6 \%$ of the respondents indicated they would distribute the surplus to individual members, but this percentage is significantly higher in Nunavut at $13.2 \%$.

Inconsistencies in the data collected required that more work be done to verify the amounts of budgets, especially for the other territories. The data for Nunavut was recalculated based on an analysis of revenue data and, as such, is sufficiently reliable to give a general idea of amounts of budgets for social economy organisations and their importance for the economy of Nunavut.

Table 6.6 lists the original data for all the territories and the recalculated data for Nunavut. The 32 Nunavut social economy organisations for which reliable operating budgets could be obtained list a total budget of $\$ 14,364,228$. Dividing this by the 32 organisations we find that the average budget is $\$ 448,882$. As stated above, given that these 32 organisations are a fairly representative sample of the 295 social economy organisations listed

Table 6.6 Budgetary data

\begin{tabular}{lcc}
\hline & All Territories & Nunavut \\
\hline Number of Respondents Listing Operating Budget & 130 & 32 \\
Total Operating Budget of Social Economy Organizations & $\$ 52,443,330$ & $\$ 14,364,228^{*}$ \\
Average Budget per Organization & $\$ 403,410$ & $\$ 448,882^{*}$ \\
Standard Deviation & $\$ 804,242$ & $\$ 824,237$ \\
\hline
\end{tabular}


in the 2008 version of the SERNNoCa census, we can state that the social economy organisations in Nunavut manage approximately $\$ 132$ million in funds each year.

While government grants account for the largest amount of revenue at $46 \%$ of total revenue, sales of goods and services (33\%) and memberships and subscriptions (145) are also important sources of revenue.

\section{General needs}

The respondents were asked a series of questions about issues related to their general needs. The first of these questions asked how much collaboration their organisation has with other social economy organisations such as non-profits, voluntary organisations, or co-operatives. Most organisations have some degree of collaboration. At the same time, there is less collaboration in Nunavut compared to the territories as a whole. In all territories, $31 \%$ of organisations collaborate a lot with similar organisations, while in Nunavut this percentage is only $17.6 \%$

Respondents were asked the degree to which a series of issues was a problem for their organisation. Figure 6.7 lists the responses to these questions. Finding funding was clearly the most important overall need of the social economy organisations responding to the questionnaire. Of all the respondents, $55 \%$ listed it as either a moderate or serious problem. Only $15 \%$ said it was not a problem. The numbers for Nunavut were similar to the averages for all the territories.

Getting volunteers is the next most serious problems faced by the respondents in all the territories. Of all the respondents, $42 \%$ said it was either a serious or moderate problem. Just over $18 \%$ said it was not a problem. In Nunavut, the issue is less a problem than in the territories as a whole as just $23 \%$ stated it was a serious or moderate problem and $26 \%$ stated it was not a problem. In Nunavut $26 \%$ of respondents stated that getting volunteers was an issue that does not apply to them compared to only $11 \%$ in all the territories.

Providing staff training and development was the second next most important issue to respondents in Nunavut and the third most important for respondents in all the territories. Only $12 \%$ in both Nunavut and the territories as a whole said it was a problem that did not apply to them. In Nunavut a slightly higher percentage of respondents stated it was not a problem, but $47 \%$ of Nunavut respondents stated it was a serious or moderate problem.

Internal capacity in areas such as internal administrative systems, information technology, software, or databases was clearly not as important an issue as the previous three. This is especially the case in Nunavut were only $22 \%$ of respondent organisations listed it as a serious or moderate problem.

The least serious issue for most respondents was collaboration with other social economy groups. While very few organisations stated that it was not a problem that applied to them, only $13 \%$ in all the territories said it was a 


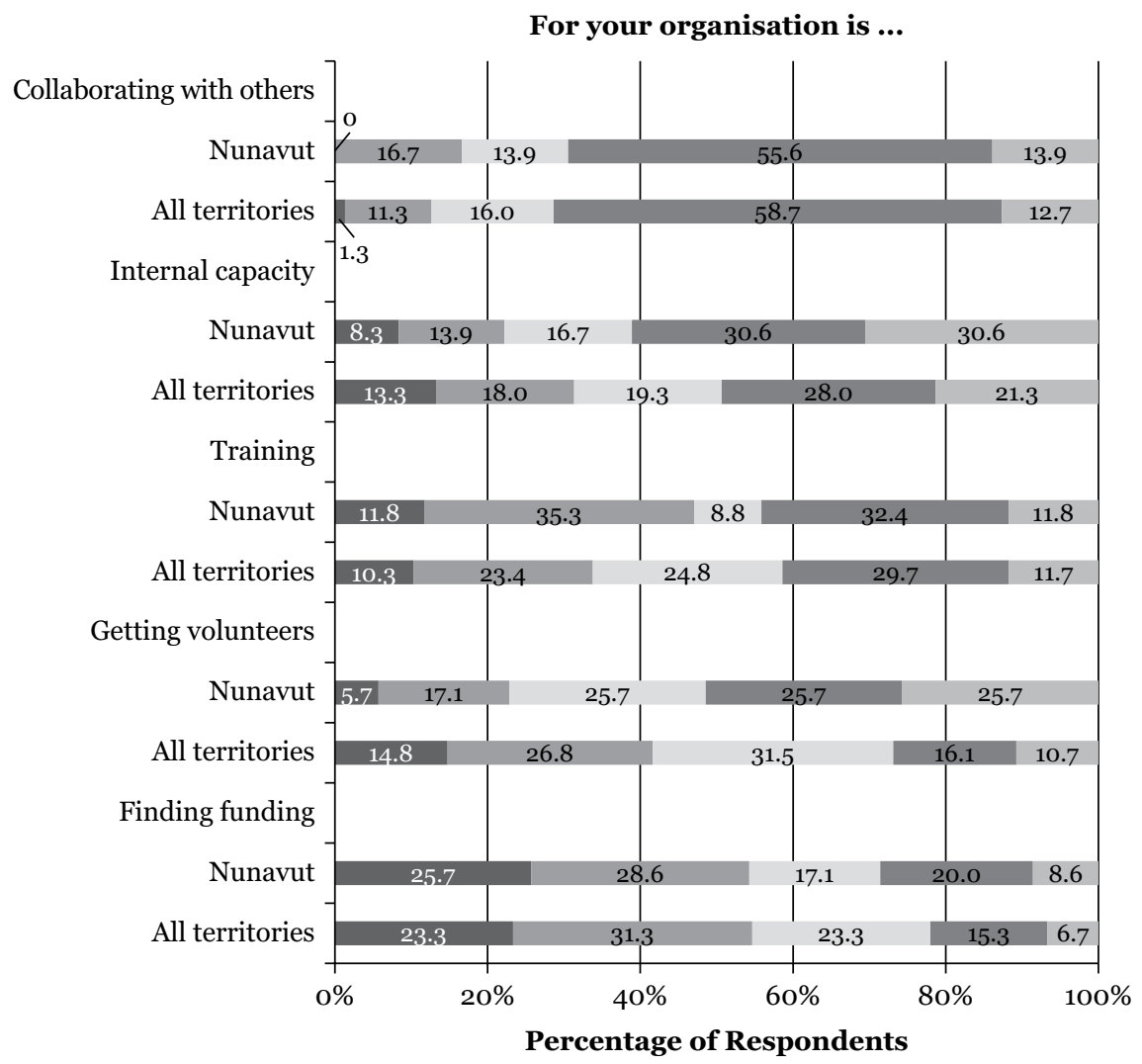

- A serious problem A moderate problem A small problem

- Not a problem Does not apply

Figure 6.7 Graph of percentage of respondents rating the statement "For your organization...."

serious or moderate problem. In Nunavut, no organisation listed it as a serious problem, and only $17 \%$ stated it was a moderate problem.

The survey also asked respondent a series of open-ended questions to allow respondents to mention issues that might not have been adequately dealt with in the questionnaire. Responses to these questions are listed below (Figure 6.8). The first asked respondents if they had any special research needs that could help their organisation better contribute to the well-being of their community.

Responses varied considerably, with some looking at general questions for Nunavut and other concerned with issues specific to their organisation.

Finally, respondent organisations were asked about concerns or problems that their organisation has had in the past. Funding surfaces as an important issue, as it was mentioned in 6 of 11 responses. 
3. Does your organisation have any special needs in terms of research that could help your organisation better contribute to the well-being of your community and region?

- if yes please specify

Responses from Nunavut respondent organisations:

- number of working artists (full time and part time) and in what mediums; amount of income from selling art. How has the development of the regional mining activities affected arts production (i.e., Artists working for mining companies)

- to expand our outreach into Nunavut, increase research opportunities related to landscape and the environment, and increase knowledge of the profession to Inuit, young people and anyone with an interest in the profession

- population growth

- coach training and recruitment

- The members need to understand the importance of cooperating with one another in order to have a healthier organisation as a community

- utilising compost to support local plants

- market research to find new customers

- We need to track our participants better, we need to understand the bottom line needs of the teachers and students in communities with respect to training in the world of skilled trades and technologies

- Research is needed on number of visitors, conversion information, economic potential of the industry, and all types of marketing research

- research for alternative education delivery

- $\quad$ support to develop our own research capacity

- language, training

- research that supports non profits in their quest to do their work more effectively- this would include arguments for increased funding from government

Figure 6.8 Responses from Nunavut respondent organisations to the question "Does your organization have any special needs in terms of research that could help your organization better contribute to the well-being of your community and region?"

\section{Summary and discussion}

Few places in the world have gone through social change with the speed and intensity that the communities of Nunavut have. In the space of 50 years, the people of this region have had to adapt themselves from a traditional migratory hunting and fishing existence based on community co-operation and self-reliance that had served them for generations to an urban lifestyle characterised by dependence and new economic and social values such as individualism, competition, and industrialism. This transition has not been easy. The loss of much of their former self-reliance and the disparagement of their traditional culture has taken a toll on these communities. This is seen in the numerous social and health challenges that are often brought to public light.

Yet despite these challenges, it is not unfair to say that the people of Nunavut have been able to survive this transition and are now looking to change the power relations that characterised their adaptation processes in the past. Rather than adapting their cultural values and lifestyles to Western patterns, they are now increasingly adapting Western values and lifestyles 
to meet their needs. While this is most evident in the creation of Nunavut, it is also evident in the ability of the people of Nunavut to develop innovative community organisations, often based on traditional cultural values, that are designed to meet the needs of their community.

Elsewhere in Canada and the rest of the world, these innovative community organisations have been called social economy organisations in that they are separate from private and government and function as an economic organisation that is based on the values of service to a community to meet social needs rather than generate profits. When given the choice, the people of Nunavut have, since the beginning of the transition, given preference to these types of organisations. This is seen, starting in the late 1950s, in the use of co-operatives as the organisation of choice to deal with economic needs. More recently, communities in the region have started to develop a range of new social economy organisations to assist in the well-being and sustainable development of their communities.

The research summarised in this chapter is an attempt to provide a portrait of the social economy in Nunavut and to outline barriers and opportunities faced by these organisations. Previous research had indicated that these organisations were facing funding and human resource difficulties. The SERNNoCa survey undertaken during 2008 confirmed the findings of these earlier studies and has given us a better understanding of some of the characteristics of these organisations. Because of the importance of co-operatives in the retail and arts and crafts sectors when compared to the other Northern territories, Nunavut has a much higher percentage of social economy organisations engaged in activities that elsewhere are provided by profit-oriented private sector organisations. Social economy organisations in Nunavut tend to be younger than those elsewhere in Canada except for co-operatives and hunter and trapper organisations. The structures of organisations in Nunavut differ from elsewhere in the North in that Nunavut has a much smaller percentage of organisations that are legally registered as charitable organisations.

Membership numbers for social economy organisation show healthy growth with a relatively high level of activity. The composition of the governing Boards of social economy organisations in Nunavut differs slightly from those elsewhere in the North in that a higher percentage of Board members in Nunavut are Indigenous, but a lower percentage are female. Another key human resource characteristic of social economy organisations in Nunavut is that fewer of these organisations use volunteers than in the other territories. In terms of human resource challenges, while obtaining and retaining Board members is not a major problem, obtaining and retaining paid staff is.

Regarding finances, the survey results confirmed previous indications that social economy organisations represent an important economic force in Nunavut. Rough calculations based on questionnaire results indicate that social economy organisations in the territory manage approximately 
$\$ 132$ million in funds each year. Government funding, as is the case for social economy organisations throughout the North, represent a higher percentage of revenues then elsewhere in Canada. Compared to the other territories, Nunavut social economy organisations receive a higher percentage of revenues from the sales of goods and services and a lower percentage from donations. In general, revenues for these organisations are on the increase. Decreasing government funding is the most serious financial challenge being faced by organisations in Nunavut.

When asked about the relative importance of a series of general needs faced by social economy organisations, Nunavut respondents identified finding funding as the most important overall need. Providing staff training and development was the second next most important issue identified by respondents in Nunavut. The least serious issue for most respondents was collaboration with other social economy groups. When asked what research would benefit the social economy in the North, responses tended to note the importance of research on general social and economic issues of concern to Nunavut. Clearly, respondent organisations are concerned about the general well-being of their communities.

Generally, the research indicates that, despite challenges, the social economy is stronger and more important in Nunavut than elsewhere. This confirms the observations found in other research that the Indigenous traditions in Nunavut continue to influence the way communities view economic development (Abele \& Southcott, 2016; Harder \& Wenzel, 2012; Southcott, 2015). The desire for a larger role for co-operative and collaborative relationships in the economy likely stems from the role these relationships played in pre-contact activities and their continued importance for traditional subsistence activities (Natcher, 2009). While extractive activities, and profit-oriented organisations that are associated with these activities, are increasing in importance in Nunavut, it is unlikely that most communities would see these activities and their organisations as an end in themselves. They are seen by many as being necessary to provide communities with necessary jobs, training, and funding (Bernauer, 2011). At the same time, it is likely that communities would use these extractive industry benefits to support more sustainable and renewable forms of long-term economic development. Social economy organisations appear to be the preferred vehicle by which Nunavut communities would like to shape their economic future.

\section{Note}

1. As the survey was not based on random sampling, probability theory-based indicators of representivity could not be used.

\section{References}

Aarluk Consulting. (2007). Not-for-Profit Groups in Nunavut-A Review. Nunavut Economic Forum. 
Abele, F. (2009). The state and the northern social economy: Research prospects. Northern Review, 30, 37-56.

Abele, F., \& Southcott, C. (Eds.). (2016). Care, cooperation and activism: Cases from the Northern social economy, University of Alberta Press.

Bernauer, W. (2011). Mining and the social economy in Baker Lake, Nunavut. Northern Ontario, Manitoba, and Saskatchewan Regional Node of the Social Economy Suite. http://usaskstudies.coop/documents/social-economy-reports-and-newsltrs.

Bouchard, M. J. (Eds.) (2011). L'économie sociale, vecteur d'innovation: l'expérience du Québec. Presses de l'Université du Québec.

Bouchard, M. J., Ferraton, C., \& Michaud, V. (2006). Database on social economy organizations: The qualification criteria. Working Papers of the Canada Research Chair on the Social Economy, Research Series no. R-2006-03.

Damas, D. (2002). Arctic Migrants/Arctic villagers: The transformation of Inuit settlement in the Central Arctic. McGill-Queen's University Press.

Harder, M. T., \& Wenzel, G. W. (2012). Inuit subsistence, social economy and food security in Clyde River, Nunavut. Arctic, 65(3), 305-318.

Impact Economics. (2008a). 2008 Nunavut Economic Outlook. Nunavut Economic Forum.

Impact Economics. (2008b). Understanding Nunavut's Non-profit Sector. Nunavut Economic Forum.

Impact Economics (2005). 2005 Nunavut Economic Outlook. Nunavut Economic Forum.

Lotz, J. (1982). The moral and ethical basis of community development: Reflections on the Canadian experience. Community Development Journal, 17(1), 27-31.

MacPherson, I. (2000). Across cultures and geography: Managing co-operatives in Northern Canada. In I. Sigurdsson \& J. Skaptason (Eds.), Aspects of Arctic and sub-Arctic history, pp.550-562. University of Iceland Press.

Natcher, D. (2009). Subsistence and the social economy of Canada's aboriginal North. Northern Review, 30, 83-98.

North Sky Consulting. (2009). Qanukkanniq? The government of Nunavut report card: Analysis and recommendations. Government of Nunavut.

Nunavut Economic Forum. (2003). Nunavut Economic Development Strategy. The Sivummut Economic Development Strategy Group.

Pell, D. (1990). Soft economics: Community organizations that can do something!. In J. Potvin (Eds.), Community economic development in Canada's North, pp. 145-167. Canadian Arctic Resources Committee.

Quarter, J., Mook, L., \& Armstrong, A. (2017). Understanding the social economy: A Canadian perspective. University of Toronto Press.

Saku, J. (2002). Modern land claim agreements and Northern Canadian aboriginal communities. World Development, 30(1), 141-151.

Southcott, C. (Ed.). (2015). Northern Communities working together: The social economy of Canada's North. University of Toronto Press.

Southcott, C., \& Walker, V. (2009). A portrait of the social economy in Northern Canada. Northern Review, 30, 13-36. Springer.

Statistics Canada. (2005). Cornerstones of Community: Highlights of the National Survey of Nonprofit and Voluntary Organizations. Ministry of Industry, Government of Canada. 